\title{
Accidental release of chlorine in Chicago: Coupling of an exposure model with a Computational Fluid Dynamics model
}

\author{
E.Y. Sanchez ${ }^{\mathrm{a}, *}$, J.E. Colman Lerner ${ }^{\mathrm{a}, \mathrm{b}}$, A. Porta ${ }^{\mathrm{a}}$, P.M. Jacovkis ${ }^{\mathrm{c}, \mathrm{d}}$ \\ ${ }^{a}$ Centro de Investigaciones del Medio Ambiente (CIMA), Facultad de Ciencias Exactas, UNLP, 47 y 115, 1900 La Plata, Argentina \\ ${ }^{\mathrm{b}}$ Centro de Investigación y Desarrollo en Ciencias Aplicadas (CINDECA, UNLP-CONICET), 47 e/ 1 y 115, 1900 La Plata, Argentina \\ ${ }^{\mathrm{c}}$ Universidad Nacional de Tres de Febrero, Argentina \\ ${ }^{\mathrm{d}}$ Universidad de Buenos Aires, Argentina
}

\section{H I G H L I G H T S}

- The FLACS-DDC coupling represents a powerful tool for planning the emergency response in cities.

- The coupling provides a continuous monitoring of the affected regions.

- The coupling allows knowing the available time for a successful intervention.

\section{A R T I C L E I N F O}

\section{Article history:}

Received 10 April 2012

Received in revised form

24 August 2012

Accepted 17 September 2012

\section{Keywords:}

Emergency management planning

Hazardous materials

Acute exposure

\begin{abstract}
A B S T R A C T
The adverse health effects of the release of hazardous substances into the atmosphere continue being a matter of concern, especially in densely populated urban regions. Emergency responders need to have estimates of these adverse health effects in the local population to aid planning, emergency response, and recovery efforts. For this purpose, models that predict the transport and dispersion of hazardous materials are as necessary as those that estimate the adverse health effects in the population.

In this paper, we present the results obtained by coupling a Computational Fluid Dynamics model, FLACS (트ame ACceleration Simulator), with an exposure model, DDC (ㅁamage Differential Coupling). This coupled model system is applied to a scenario of hypothetical release of chlorine with obstacles, such as buildings, and the results show how it is capable of predicting the atmospheric dispersion of hazardous chemicals, and the adverse health effects in the exposed population, to support decision makers both in charge of emergency planning and in charge of real-time response.

The results obtained show how knowing the influence of obstacles in the trajectory of the toxic cloud and in the diffusion of the pollutants transported, and obtaining dynamic information of the potentially affected population and of associated symptoms, contribute to improve the planning of the protection and response measures.
\end{abstract}

(c) 2012 Elsevier Ltd. All rights reserved.

\section{Introduction}

The adverse health effects of an accidental release of hazardous substances in the atmosphere continue being a matter of concern, especially in densely populated urban regions. Spatial patterns and time variations of concentration of hazardous substances, as well as potential effects on population, are necessary to aid the planning and response to an emergency. To satisfy this need, there are models that forecast the transport of hazardous substances and other models that estimate the potential effects in the exposed population. These models are necessary to develop specific

\footnotetext{
* Corresponding author.

E-mail address: yaninasanch@gmail.com (E.Y. Sanchez).
}

protocols as well as to determine and characterize the source of the emission. Furthermore they help to develop plans of response to emergencies and, if possible, may support activities of response in real time (Warner et al., 2008; Hanna et al., 2009).

\subsection{Models of atmospheric diffusion}

The purpose of the diffusion models is to provide the concentration values observed downwind of the emission source when all the input data are known. There are many classifications of atmospheric transport models, but each author uses the classification that best matches his or her approach. Models of atmospheric diffusion recommended and preferred by the US EPA can be classified into five generic classes: Gaussian models, numerical models, 
statistical or empirical models, box models and physical models. A complete list can be found on the Support Center for Regulatory Air Models, US EPA (2012e). The type of model appropriate for a particular use depends on the scale of the problem, on the level of detail of the information available as input to the model, on the level of description desired for the model output and on the waiting time available to finish the model computations (Beychok, 1994; Dandrieux et al., 2006; Doury, 1988).

The Gaussian and box models are broadly used in the procedures for risk analysis, and they provide fast estimations of the diffusion. Their results are generally reliable when describing the behavior of a toxic cloud transported over a plain terrain without obstacles. However, the fact that the terrain is represented as a flat surface, without taking into account the effect due to buildings and other obstacles, conditions the results and, therefore, their application. Besides, the fact that they consider that all variables remain unchanged with time (stationary hypothesis) acts as an important constraint when trying to apply them in actual emergency situations. This assumption allows to significantly simplify the computations, but its flaw is that it does not take into account perturbations such as changes in the direction and magnitude of the wind (Hanna and Drivas, 1987; Hanna and Strimaitis, 1988; Reynolds, 1992; Delaunay, 1996).

The increasing speed of the modern computers and the development of more efficient methods in Computational Fluid Dynamics (CFD) models have encouraged the study of complex environmental problems using this type of numerical models. As Hanna et al. (2009) concluded, the results obtained with these models are more accurate than those obtained with simpler models, because the wind velocity is taken as a given function of position and time, instead of being a constant value or a function of height. The difference in the results is seen more clearly in those regions of study were large obstacles exist (Gavelli et al., 2008; Long et al., 2009). Therefore, regarding chemical emergencies, CFD models are excellent tools for planning the response in densely built areas.

CFD models have the limitation of being extremely complex and also require an impressive computational cost, so that their application for managing emergencies in real time is unfeasible (Sklavounos and Rigas, 2005). Comparative studies carried on by Hanna et al. (2008) using a CFD model, FLACS (FLame ACceleration Simulator), concluded that the predictions are very good.

The FLACS CFD model - whose outputs provided by Hanna et al. (2009) were implemented in this work - was originally developed to simulate explosions. Currently it is also employed to simulate other phenomena, such as diffusion of air pollutants, and its application is supported by several validation studies (Hanna et al., 2004a, 2009; GexCon US, 2012). The Navier-Stokes equations are numerically solved by means of a finite-volume method and a $\kappa-\varepsilon$ Reynolds stresses closure model over a Cartesian mesh. Hjertager $(1985,1986)$ details the equations used in FLACS and Hjertager et al. (1988a, 1988b) analyze different field experiments applied when developing FLACS. A more detailed description of FLACS may be consulted in Warner et al. (2008) and in Hanna et al. (2004a, 2004b).

Considering the useful properties of the CFD FLACS model, and the similitude of the scenarios analyzed by Hanna et al. (2009) with those of interest for our research team, we begin analyzing the potentiality and limitations of coupling the FLACS CFD model with the exposure model DDC (Damage Differential Coupling) described below, regarding their application in our region.

\subsection{Human exposure models}

As US EPA (2012c) defines, human exposure modeling relates pollutant concentrations in the larger environmental media to pollutant concentrations in the immediate exposure media with which a human population has direct contact.

To know how and where people are exposed to air pollutants is important both to identify persons under risk and to reduce this risk. The exposure models offer a way of predicting exposures and affected areas under different scenarios (US EPA, 2012d). During emergencies an intense pressure exists to decide as soon as possible what measures to take. In those situations, the AEGLs (Acute Exposure Guideline Levels), ERPGs (Emergency Response Planning Guidelines) and TEELs (Temporary Emergency Exposure Limits) indices become extremely useful. These reference values provide basic information on adverse health effects in the population due to acute and direct exposure to specific chemicals.

The preferred toxicological index is AEGL. When it is not possible to apply AEGL it is recommended to apply the ERPG index, the TEEL index being a last resource (Ruiz Boada et al., 2003; US EPA, 2012a). AEGLs represent threshold exposure limits for the general public and are applicable to emergency exposure periods ranging from $10 \mathrm{~min}$ to $8 \mathrm{~h}$. The NAC/AEGL's standing operating procedures define the concept of AEGLs as threshold exposure limits for the general population including infants and children, and other individuals who may be susceptible. Three different health effects levels were established, corresponding to increasingly severe symptoms: AEGL 1, AEGL 2, and AEGL 3 (National Research Council, 2001; Stage, 2004). The current status of this project can be found by consulting the EPA website (US EPA, 2012a). The compromise, accepted by several national and international agencies, consisting in focusing the research efforts in AEGLs, may constrain the development of new ERPGs and TEELs (Ruiz Boada et al., 2003).

Since the toxicological indices described above are comparable in terms of levels of adverse health effects, we shall denote different levels of the indices of reference with the acronym HEL (Health Effects Level); for example, AEGL 1 corresponds to HEL 1 . This classification is detailed in Section 4.

As stated in Acquesta et al. (2011), in an emergency situation the estimation of the HEL due to exposure to a toxic cloud is not generally included in widely used software, or it is taken into account in a very simple way without considering time variation of concentration. The models often take into account only the simulated maximum concentration, thus providing overestimated results of the effects on health. An improved approach is presented in the method named DDC (Damage Differential Coupling), which obtains a detailed estimate of HEL through the analysis of time variation of concentration. The method estimates maximum and minimum levels (hereinafter referred to as maximum damage and minimum damage, respectively) of health effects caused by the exposure to a toxic cloud, using a recursive algorithm for that purpose (Sanchez, 2012; Sanchez et al., 2010, 2011, 2012a, 2012b). DDC applies a methodology of differential analysis which ensures that the expected effect on health is among the maximum and minimum damage mentioned. To estimate the HEL as a function of exposure time, DDC assumes that there is a continuous field of the toxicological indices mentioned for time and concentration, and that the incremental estimation of the maximum and minimum damage by means of exposure differentials is not commutative. A more detailed description of the methodology developed for the DDC approach may be consulted in Acquesta et al. (2011).

Finally, note that the DDC method is applicable to acute exposures: therefore it employs the indices mentioned in this section as a platform, incorporating the exposure characteristics described in the technical reports that justify these values (Craig et al., 2000; ERPG and WEEL, 2007; US EPA, 2012a).

Due to its particular characteristics, DDC method becomes extremely useful in triage situations, when resources are scarce and there is no room for any mistake. 


\section{Coupling of FLACS and DDC models}

Even though FLACS (or other CFD model) may reproduce the details of the flow movements more accurately than the simpler models broadly employed (Hanna et al., 2009), this level of detail in emergency situations becomes insufficient if a joint analysis with toxicological aspects of the exposed population is not carried out. In this sense, it is crucial to estimate where and when the threshold exposure limits are exceeded.

In this study, the continuous input data supplied to DDC are the concentrations simulated by Hanna et al. (2009) at each cell of the mesh, on the plane $Z=1 \mathrm{~m}$, where $Z$ is the height over the terrain level in the FLACS simulation. Potential effects on health are determined by means of the toxic load formula which is based on the concentration and the exposure time. Consequently, DDC estimates the HEL on the population exposed to the toxic cloud.

In this paper, the coupled model system FLACS-DDC is employed to simulate the effects of a release of chlorine near downtown Chicago, IL. With this example we intend to illustrate the importance of this coupled model system for planning the response to emergency in cities. Improvements in planning, plus real time systems providing alarms, can contribute significantly to better responses to emergencies.

\section{Description of the hypothetical release near downtown Chicago}

We have taken Chicago as scenario of the case study, because Hanna et al. (2009) kindly allowed us to use their data and runs. They choose a source location ( $\mathrm{N} 41.860283, \mathrm{~W} 87.630733$ ) at an important railway junction, near downtown Chicago. The Chicago scenario involves an actual location, of course, but the release is purely hypothetical. As may be seen in Fig. 1, a flat and open terrain in the immediate area of the emission source exists, composed generally of grass, trees and bushes, and areas of sand/gravel. Inside the proposed scenario there is also the Chicago River, located around $300 \mathrm{~m}$ west of the emission source. Hanna et al. simulated a leak of pressurized chlorine from a tank on a freight train through a hole with a $10 \mathrm{~cm}$ diameter. A $225 \mathrm{~kg} \mathrm{~s}^{-1}$ release rate of chlorine over during $5 \mathrm{~min}$ is assumed.

Hanna et al. suppose very stable atmospheric conditions and light winds $\left(3 \mathrm{~m} \mathrm{~s}^{-1}\right)$ for their simulation. The vertical velocity gradient is taken into account at the inflow. The mean velocities wind profile is logarithmic in both simulations.

Two scenarios were analyzed: in scenario 1 (see Fig. 1a) the wind is from the south and the cloud is transported to the north, toward a densely built area, characterized by tall buildings, with a population density of around 3949 individuals per $\mathrm{km}^{2}$; in scenario 2 (see Fig. 1b) the wind is from the east and the cloud is transported to the west through a commercial/residential area, with a population density of around 16,072 individuals per $\mathrm{km}^{2}$ (Wendell Cox Consultancy, 2012). For modeling purposes, scenario 1 is represented by a $5 \mathrm{~km} \times 2.5 \mathrm{~km}$ mesh (in directions from north to south and from east to west, respectively), while scenario 2 is represented by a $2 \mathrm{~km} \times 4.5 \mathrm{~km}$ mesh (in directions from north to south and from east to west, respectively). For scenario 1, the vertical size of the domain is $500 \mathrm{~m}$ and, for scenario 2 , the vertical size is $150 \mathrm{~m}$. Near the source, Hanna et al. (2009) use cells with width $=6 \mathrm{~m}$ and height $=2 \mathrm{~m}$ at the initial time; however, the size of the cells increases as the cloud moves away from the emission source. A $30 \mathrm{~s}$ time step is employed. More details of the Chicago scenario may be consulted in Hanna et al. (2009).

In this paper we are focusing on chlorine for several reasons. On the one hand, chlorine is one of the most widely used chemical substances in industry. Besides, given its density (it is 2.5 times as
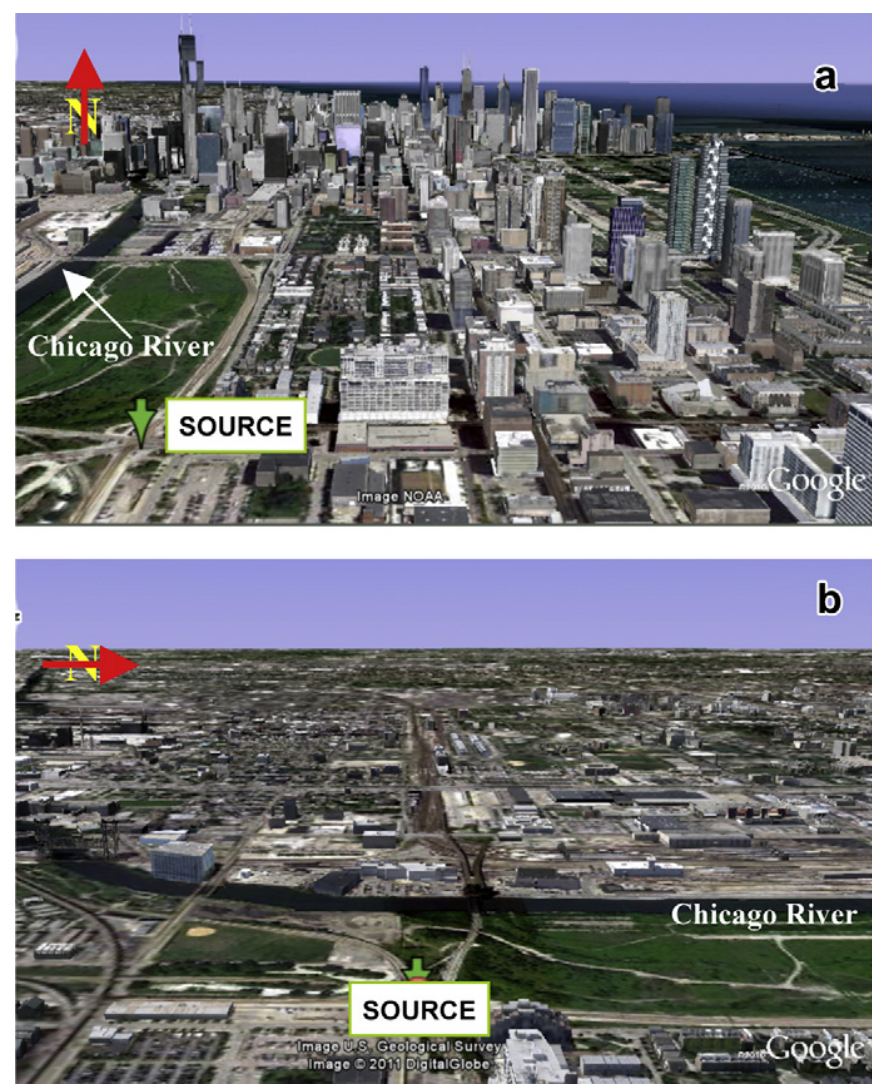

Fig. 1. Aerial view of study area: Scenarios 1 (a) and 2 (b). In the first one the railway junction is visualized viewing north. In the same picture the Chicago River can be seen to the left of the source, and also the tall buildings to the North. In (b) the same junction is seen, viewing west. In this picture it may be noted that smaller buildings dominate and the Chicago River is transversal to the wind direction assumed. Source: Google maps, 2011.

heavy as air) it forms a dense cloud that remains close to the ground when moving. Due to the presence of buildings and other structures, more sophisticated algorithms are required for computations to be useful for an accurate prediction. The body's response to chlorine inhalation depends on the concentration and the total exposure time, and can range from sensory detection, sensory irritation and bronchial spasm reflex to death by pulmonary edema or lack of oxygen during an asthma attack. Amoore and Hautala (1983) concluded that the odor threshold (sensory detection) is $0.31 \mathrm{ppmv}$, and a range of $0.2-0.4 \mathrm{ppm}$ has been reported in other studies (Fauske and Epstein, 1988; Ruiz Boada et al., 2003; National Research Council, 2004; MANHAZ, 2006; Hansen et al., 2007).

For the substance in question, AEGL will be the index to be used by DDC due to its availability and priority in the hierarchy mentioned in Section 1.2. AEGL values for chlorine can be found in Table 1.

Table 1

AEGLs for chlorine, corresponding to the update of the U.S. EPA (2012a) July 2006 final statement.

\begin{tabular}{lccccc}
\hline Index & \multicolumn{7}{l}{ Exposure time (minutes) } \\
\cline { 2 - 6 } & \multicolumn{1}{c}{10} & 30 & 60 & 240 & 480 \\
\hline AEGL-1 $\left(\mathrm{mg} \mathrm{m}^{3}\right)$ & 1.5 & 1.5 & 1.5 & 1.5 & 1.5 \\
AEGL-2 $\left(\mathrm{mg} \mathrm{m}^{3}\right)$ & 8.3 & 8.3 & 5.9 & 3 & 2.1 \\
AEGL-3 $\left(\mathrm{mg} \mathrm{m}^{3}\right)$ & 147.7 & 82.7 & 59.1 & 29.5 & 21 \\
AEGL-1 $(\mathrm{ppm})$ & 0.5 & 0.5 & 0.5 & 0.5 & 0.5 \\
AEGL-2 $(\mathrm{ppm})$ & 2.8 & 2.8 & 2 & 1 & 0.71 \\
AEGL-3 $(\mathrm{ppm})$ & 50 & 28 & 20 & 10 & 7.1 \\
\hline
\end{tabular}




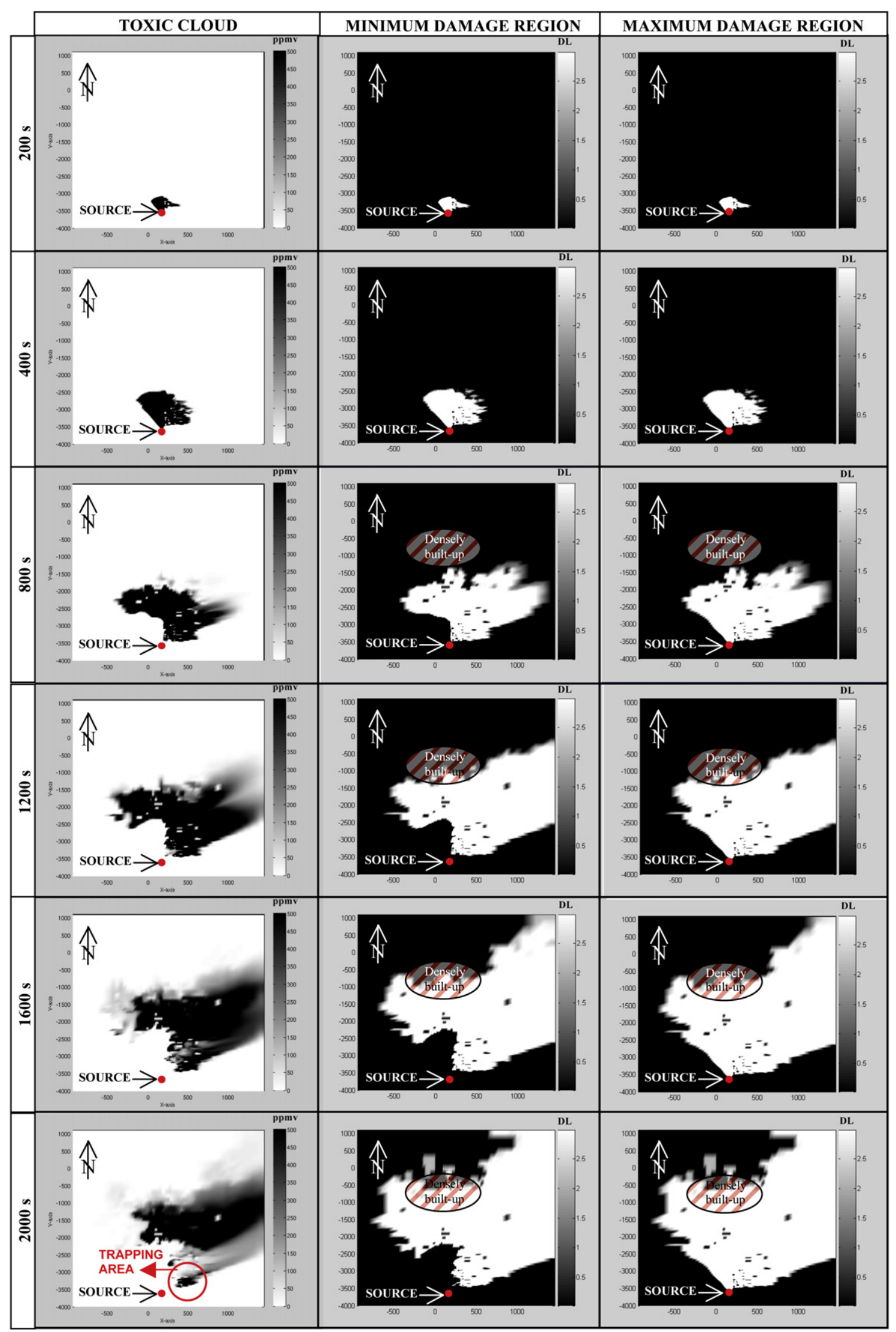

Fig. 2. Representation of the evolution of toxic cloud and hazard regions generated by DDC, for Chicago scenario 1 (south wind), where 0.31 ppmv contours are shown, for $t=200$, $400,800,1200,1600$ and $2000 \mathrm{~s}$; where $t$ is the time after the chlorine release starts. 


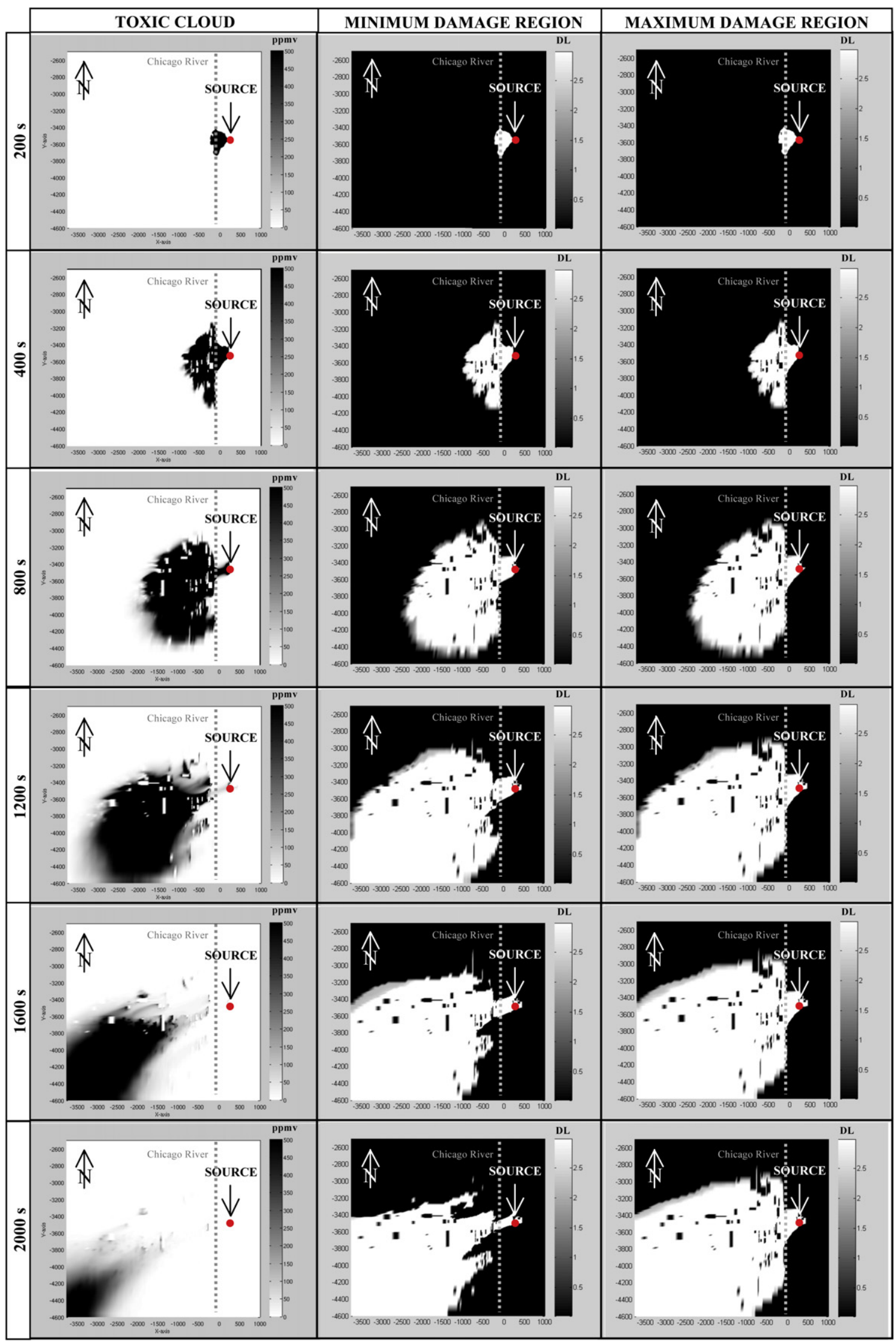

Fig. 3. Representation of the evolution of toxic cloud and hazard regions generated by DDC, for Chicago scenario 2 (east wind), where 0.31 ppmv contours are shown, for $t=200$, $400,800,1200,1600$ and $2000 \mathrm{~s}$; where $t$ is the time after the chlorine release starts. 
Table 2

Population, population density and area of Chicago neighborhoods reached by the chlorine cloud. Source: Wendell Cox Consultancy (2012).

\begin{tabular}{lllc}
\hline Neighborhood & $\begin{array}{l}\text { Population 2000 } \\
\text { (individuals) }\end{array}$ & $\begin{array}{l}\text { Population density } \\
\left.\text { 2000 (individuals } \mathrm{km}^{-2}\right)\end{array}$ & $\begin{array}{l}\text { Land area } \\
\left(\mathrm{km}^{2}\right)\end{array}$ \\
\hline Loop & 16,388 & 3958 & 4.14 \\
Lower West Side & 44,031 & 6073 & 7.25 \\
Near South Side & 95,09 & 2041 & 4.66 \\
Near West Side & 46,419 & 3145 & 14.76 \\
\hline
\end{tabular}

\section{Results and discussion}

Hanna et al. (2009) included examples of three dimensional representations of the FLACS simulations of a few chlorine concentrations, providing us a complete 3-D time-dependent chlorine concentrations data file. In Figs. 2 and 3, 2-D graphical representations are shown of the results of the FLACS-DDC coupled model system, for scenarios 1 and 2 respectively. Each Figure presents separate results for the following simulation times: $200,400,800,1200,1600$ and $2000 \mathrm{~s}$, after the chlorine release was initiated. These figures represent snapshots of the continuous simulation of the coupled system FLACS-DDC and show regions bounded by a $0.31 \mathrm{ppm}$ concentration for the toxic cloud and zero HEL for damage regions. Note that the representation of the toxic cloud shows time-averaged concentrations, using the same averaging time for each simulation time; however, the representation of the damage regions shows the total exposure over the entire time period of release up to the current time.

\subsection{Descriptive analysis}

The results of the simulation with FLACS showed that, for scenario 1 (see Fig. 2), the chlorine cloud moves with greater velocity and lesser dilution through a plain and open terrain, spreading out more than $1000 \mathrm{~m}$ distance in wind direction from the emission source during the first $400 \mathrm{~s}$. When the cloud encounters the densely-built area at the edge of the open area it dilutes at a larger rate due to the increased turbulent mixing near the buildings. Further, it is seen that a volume of chlorine becomes trapped within the southwestern area of tall buildings, even at large times after the release was initiated.

Although the southern wind in this scenario may suggest a straightforward movement of the cloud toward the north, the displacement to the right seen in Fig. 2 may be caused by the smaller buildings to the east, permitting the cloud to continue its trajectory over the region with less dilution. Meanwhile, the regions with adverse health effects simulated with DDC reflect this situation since the length of almost all the front of the maximum and minimum regions is about $2500-3000 \mathrm{~m}$ downwind (at that distance tall buildings predominate).

For scenario 2, as may be seen in Fig. 3, the chlorine cloud extends about $45 \%$ farther than for scenario 1 . As is well explain in Hanna et al. (2009), this happens because the cloud experiences a less turbulent mixture, and therefore a lesser dilution due to the smaller buildings that it finds over its trajectory. On the other hand, the simulation of FLACS represents very well the effects associated with the channel of the Chicago River due to the lateral spreading of the cloud. This is visualized more clearly when representing the maximum regions, because they conserve their shape as time passes by.

The scale to the right of each graph of the Figs. 2 and 3 has the following interpretation concerning the magnitude of HEL (dimensionless). The range, $0 \leq \mathrm{HEL}<1$ represents exposure levels that would produce a light odor, taste or other light sensorial irritation (HEL $=0$ corresponds to 0.31 ppmv odor threshold). The range $1 \leq \mathrm{HEL}<2$ represents exposure levels that would affect the population at large (including susceptible people such as children, asthmatic and elderly people, and people with other illnesses). These effects are transient and reversible once the exposure ends. For $2 \leq \mathrm{HEL}<3$ the above population could experience serious and/ or irreversible lasting effects and their ability to escape could be inhibited. For $\mathrm{HEL}=3$, the population may experience lifethreatening effects and might die. Finally, each integer HEL between 1 and 3 corresponds to the levels 1, 2 and 3 of the AEGL presented in Table 1.

Diagrams of minimum (second column) and maximum (third column) damage regions of simulation with DDC, in Figs. 2 and 3, permit to recognize the extreme values of the expected adverse health effects and, at the same time, permit us to assume that the

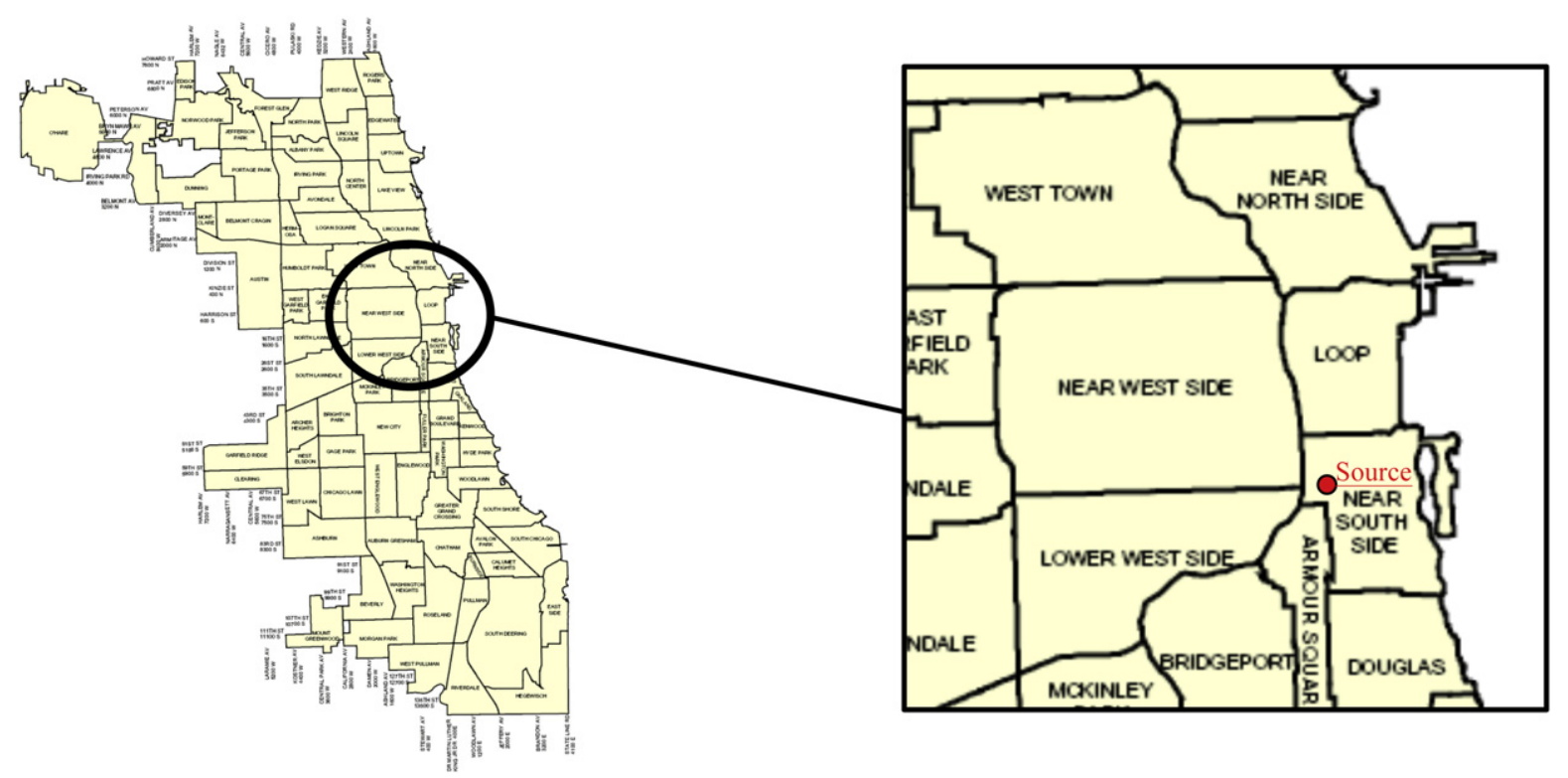

Fig. 4. Chicago Neighborhood Map. Source: Official Website for the State of Illinois (2012). 
Table 3

Area and affected population (AP) in maximum and minimum damage regions, according to ranges of HEL, of scenario 1.

\begin{tabular}{|c|c|c|c|c|c|}
\hline \multirow[t]{2}{*}{ Time $(\mathrm{s})$} & \multirow[t]{2}{*}{ HEL } & \multicolumn{2}{|c|}{ Maximum damage region } & \multicolumn{2}{|c|}{ Minimum damage region } \\
\hline & & Area $\left(\mathrm{km}^{2}\right)$ & $\mathrm{AP}$ (individuals) & Area $\left(\mathrm{km}^{2}\right)$ & AP (individuals) \\
\hline \multirow[t]{4}{*}{200} & $1 \leq \mathrm{HEL}<2$ & 0.003 & 12 & 0.002 & 11 \\
\hline & $2 \leq \mathrm{HEL}<3$ & 0.005 & 23 & 0.005 & 23 \\
\hline & $\mathrm{HEL}=3$ & 0.082 & 389 & 0.082 & 389 \\
\hline & Total & 0.090 & 424 & 0.090 & 423 \\
\hline \multirow[t]{4}{*}{400} & $1 \leq \mathrm{HEL}<2$ & 0.034 & 147 & 0.033 & 143 \\
\hline & $2 \leq \mathrm{HEL}<3$ & 0.028 & 121 & 0.028 & 118 \\
\hline & $\mathrm{HEL}=3$ & 0.487 & 2084 & 0.485 & 2074 \\
\hline & Total & 0.550 & 2352 & 0.546 & 2335 \\
\hline \multirow[t]{4}{*}{800} & $1 \leq \mathrm{HEL}<2$ & 0.288 & 894 & 0.282 & 873 \\
\hline & $2 \leq \mathrm{HEL}<3$ & 0.106 & 327 & 0.087 & 270 \\
\hline & $\mathrm{HEL}=3$ & 2.040 & 6320 & 1.900 & 5887 \\
\hline & Total & 2.434 & 7541 & 2.269 & 7030 \\
\hline \multirow[t]{4}{*}{1200} & $1 \leq \mathrm{HEL}<2$ & 0.083 & 254 & 0.080 & 244 \\
\hline & $2 \leq \mathrm{HEL}<3$ & 0.168 & 516 & 0.159 & 486 \\
\hline & $\mathrm{HEL}=3$ & 4.000 & 12,274 & 3.720 & 11,416 \\
\hline & Total & 4.251 & 13,044 & 3.959 & 12,146 \\
\hline \multirow[t]{4}{*}{1600} & $1 \leq \mathrm{HEL}<2$ & 0.063 & 178 & 0.060 & 170 \\
\hline & $2 \leq \mathrm{HEL}<3$ & 0.319 & 906 & 0.405 & 1149 \\
\hline & $\mathrm{HEL}=3$ & 5.370 & 15,236 & 4.890 & 13,874 \\
\hline & Total & 5.752 & 16,320 & 5.355 & 15,193 \\
\hline \multirow[t]{4}{*}{2000} & $1 \leq \mathrm{HEL}<2$ & 0.003 & 8 & 0.000 & 0 \\
\hline & $2 \leq \mathrm{HEL}<3$ & 0.364 & 940 & 0.414 & 1070 \\
\hline & $\mathrm{HEL}=3$ & 6.250 & 16,153 & 5.720 & 14,782 \\
\hline & Total & 6.617 & 17,101 & 6.134 & 15,852 \\
\hline
\end{tabular}

expected adverse health effects level will be found between these values. During the evolution of the toxic cloud the difference between the maximum and the minimum damage regions is usually small, and the mean value approximates the expected adverse health effects value.

\subsection{Quantitative analysis}

During a disaster, knowing how many people are potentially affected, and to what extent, in an appropriate time frame, gives the decision makers the tools to reach conclusions concerning, among others, the time available to evacuate those who will be affected in a near future, the amount of people who will need immediate medical care according to how they are affected, and the logistics that will be necessary to respond to the emergency. Any detail that may contribute to the assessment of weaknesses, response capacity and threats is very important for risk management.

In Table 2 the characteristics of the neighborhoods affected by chlorine cloud (population, covered area and population density) are listed, and these neighborhoods are presented in the Fig. 4.

In Tables 3 and 4 the sizes of the maximum and minimum damage regions are presented as well as the population affected by the chlorine cloud under different ranges of HEL for the different times of simulation. The time is counted from the start of the chlorine release. The distribution of people affected in terms of HEL is representative of the characteristics of the release, detailed in Section 3: type and rate of emission, substance emitted and atmospheric conditions. All these factors contribute to the formation of a dense cloud, able to remain during a long period of time. For this reason, the results are intuitive since the number of people affected at the highest HEL is larger than the number affected at the lower HEL.

The dynamic of the damage regions shows how the chlorine cloud moves with greater velocity for scenario 2 than for scenario 1 . This fact is indicated by the contrast between the covering areas of maximum and minimum damage regions (see Fig. 5).
Table 4

Area and affected population (AP) of maximum and minimum damage regions, according to ranges of HEL, of scenario 2 .

\begin{tabular}{|c|c|c|c|c|c|}
\hline \multirow[t]{2}{*}{ Time (s) } & \multirow[t]{2}{*}{ HEL } & \multicolumn{2}{|c|}{ Maximum damage region } & \multicolumn{2}{|c|}{ Minimum damage region } \\
\hline & & Area $\left(\mathrm{km}^{2}\right.$ & AP (individuals) & Area $\left(\mathrm{km}^{2}\right)$ & AP (individuals) \\
\hline \multirow[t]{4}{*}{200} & $1 \leq \mathrm{HEL}<2$ & 0.003 & 10 & 0.003 & 9 \\
\hline & $2 \leq \mathrm{HEL}<3$ & 0.004 & 14 & 0.004 & 14 \\
\hline & $\mathrm{HEL}=3$ & 0.084 & 291 & 0.084 & 292 \\
\hline & Total & 0.091 & 315 & 0.091 & 315 \\
\hline \multirow[t]{4}{*}{400} & $1 \leq \mathrm{HEL}<2$ & 0.038 & 120 & 0.039 & 121 \\
\hline & $2 \leq \mathrm{HEL}<3$ & 0.063 & 198 & 0.063 & 197 \\
\hline & $\mathrm{HEL}=3$ & 0.547 & 1716 & 0.543 & 1702 \\
\hline & Total & 0.648 & 2034 & 0.644 & 2020 \\
\hline \multirow[t]{4}{*}{800} & $1 \leq \mathrm{HEL}<2$ & 0.254 & 1035 & 0.236 & 961 \\
\hline & $2 \leq \mathrm{HEL}<3$ & 0.107 & 437 & 0.097 & 397 \\
\hline & $\mathrm{HEL}=3$ & 2.443 & 9962 & 2.395 & 9769 \\
\hline & Total & 2.804 & 11,434 & 2.728 & 11,127 \\
\hline \multirow[t]{4}{*}{1200} & $1 \leq \mathrm{HEL}<2$ & 0.095 & 424 & 0.089 & 397 \\
\hline & $2 \leq \mathrm{HEL}<3$ & 0.205 & 913 & 0.165 & 736 \\
\hline & $\mathrm{HEL}=3$ & 4.820 & 21,460 & 4.610 & 20,525 \\
\hline & Total & 5.120 & 22,797 & 4.864 & 21,658 \\
\hline \multirow[t]{4}{*}{1600} & $1 \leq \mathrm{HEL}<2$ & 0.016 & 67 & 0.009 & 41 \\
\hline & $2 \leq \mathrm{HEL}<3$ & 0.267 & 1152 & 0.163 & 702 \\
\hline & $\mathrm{HEL}=3$ & 5.120 & 22,067 & 4.480 & 19,308 \\
\hline & Total & 5.403 & 23,286 & 4.652 & 20,051 \\
\hline \multirow[t]{4}{*}{2000} & $1 \leq \mathrm{HEL}<2$ & 0.006 & 26 & 0.000 & 0 \\
\hline & $2 \leq \mathrm{HEL}<3$ & 0.251 & 1089 & 0.013 & 55 \\
\hline & $\mathrm{HEL}=3$ & 5.160 & 22,412 & 3.900 & 16,940 \\
\hline & Total & 5.417 & 23,527 & 3.913 & 16,995 \\
\hline
\end{tabular}

Note that for simulation times higher than $1200 \mathrm{~s}$ (Figs. 2 and 3) there are areas with concentrations below the maximum concentration reached from the start of the release of chlorine.

DDC also allows to estimate the affected population. For this purpose, we used the data obtained from the 2000 census (Wendell Cox Consultancy, 2012), and a hypothetical distribution of the population based on the characteristics of the neighborhoods. The estimation of DDC shows that after $1200 \mathrm{~s}$ from the start of the chlorine release in scenario 2, at least 21,658 (and at most 22,797) individuals could potentially be affected by the chlorine cloud, while for a $2000 \mathrm{~s}$ simulation time the potentially affected population could be at least 16,995 (and up to 23,527).

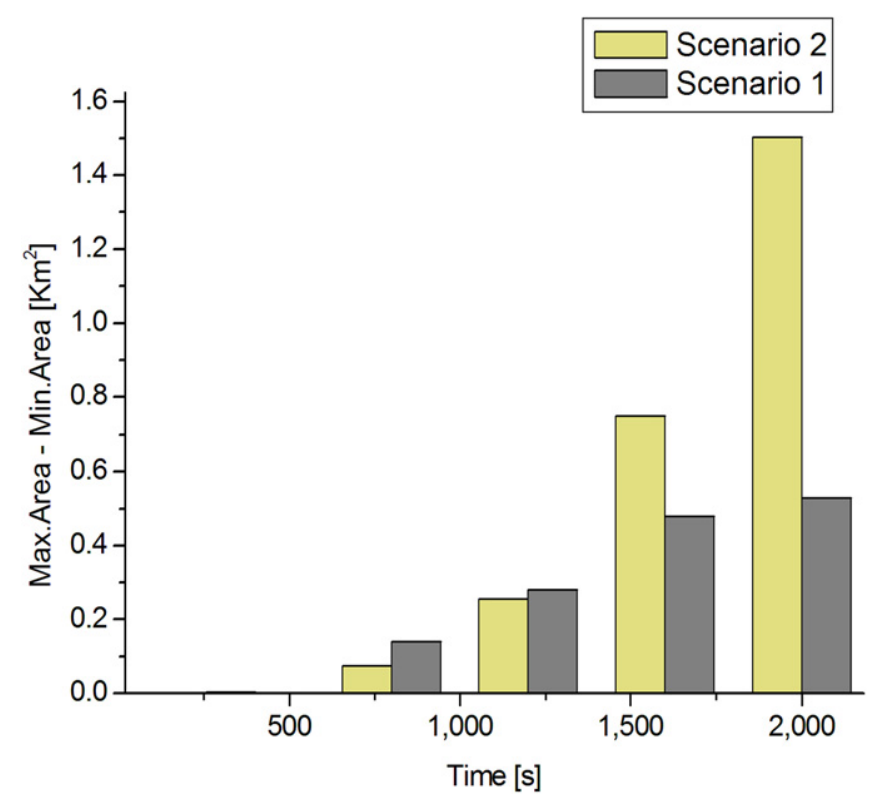

Fig. 5. Analysis of areas of maximum and minimum damage regions: Difference between the size of maximum and minimum regions as time passes by for both scenarios, where time is the exposure time after the chlorine release starts. 

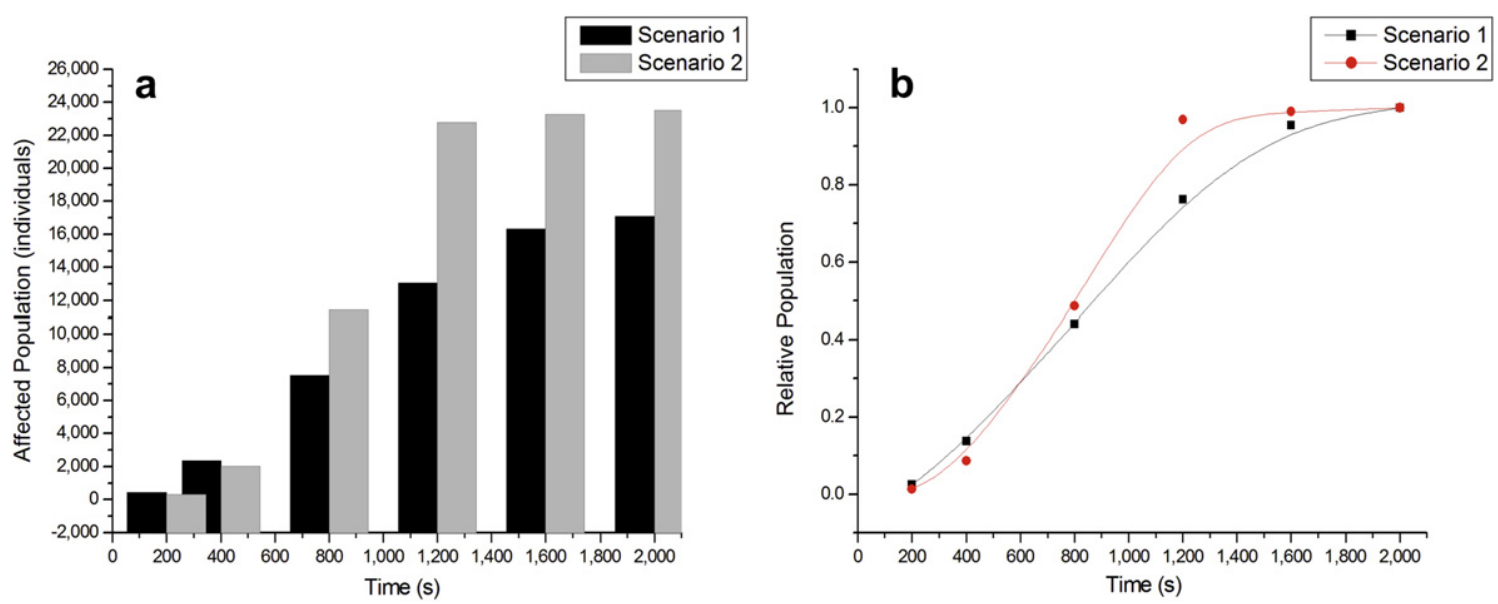

Fig. 6. Analysis of affected population. (a) Population potentially affected in scenarios 1 and 2, as function of the time after the chlorine release starts. (b) Comparison of the relative

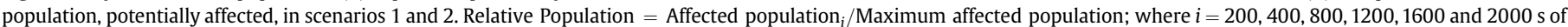
simulation time.

Finally, in Fig. 6 an analysis of the affected population for scenarios 1 and 2 is presented. For this reason a variable denoted Relative Population is defined, namely

Relative Population $=\frac{\text { affected population }_{i}}{\text { maximum affected population }}$;

where (in Fig. 6) $i=200,400,800,1200,1600$ and 2000 s are the simulation times. By means of this variable we can detect how the development of the chlorine cloud is influenced by the local distribution of buildings. This explains why the rate of growth of affected population in Fig. $6 \mathrm{~b}$ decreases after $1200 \mathrm{~s}$ for scenario 1 (at $1200 \mathrm{~s}$ the cloud reaches the densely built area, characterized by its tall buildings). Instead, for scenario 2 it can be observed that an increasing rate (greater than for scenario 1 ) exists till time $=1200 \mathrm{~s}$ : at this time the boundaries of the Cartesian meshing is reached. Were it not for this boundary, the rate of growth could have been maintained, because of the characteristics of the terrain and because of the magnitude of the leakage that requires more time and distance to dilute the cloud. Finally, in Fig. 6a we present the comparison between the individuals potentially affected for both scenarios.

It is clear in the graph that for scenario 2 more people would be affected by the chlorine cloud than for scenario 1 . However, the final covered area for scenario $2\left(5.417 \mathrm{~km}^{2}\right)$ is less than for scenario $1\left(6.617 \mathrm{~km}^{2}\right)$. This conclusion is directly related to the fact that the population density is greater for scenario 2 than for scenario 1.

This quantitative information, together with the graphic representations of the damage regions and of the evolution of the toxic cloud, may be employed as a valuable tool for the risk analysis. To know continuously in time how many people are potentially affected, and how much, is important to decision makers in a chemical emergency.

The use of the advantages of these tools goes, hand by hand, with the necessity of having complete and updated information about the population of the studied scenarios, in order to be able to adequately represent the situation.

\section{Conclusions}

The FLACS-DDC coupled model system allows the creation of a powerful tool for planning the response when facing an emergency in cities, due to its capacity for describing the flow in densely built areas; its accuracy to estimate the potential adverse health effects in the exposed population by means of a minimum estimation and a maximum estimation; its versatility to use different indices of acute exposure and, finally, its capacity to estimate the time evolution in the affected areas and the number of individuals reached by the toxic cloud.

The coupled model system also offers the possibility of a continuous follow-up, a progressive estimation of adverse health effects, and a more descriptive approach of the evolution of the damage regions than other currently used methodologies, such as ALOHA (US EPA, 2012b). These are significant advantages for the integral managing of emergencies, because they allow a better understanding of the situation and of the available time for a successful intervention.

The output of the simulation with FLACS shows how the developing of the toxic cloud is influenced by the local distribution of the buildings. The chlorine cloud is transported along a large distance when the terrain is flat and a less turbulent mixture exists, but once the cloud reaches the area where there are many tall buildings the cloud dilutes quickly. Meanwhile, the output of the simulation with DDC reflects this situation through regions of damage, restricting the length of the front of progress to around 2500-3000 $\mathrm{m}$ in the wind direction. On the other hand, the simulation with FLACS shows how high concentrations between tall buildings may last, even when the cloud is not there anymore; besides, it shows how the toxic cloud may follow the slope of the terrain.

The results show how knowing the influence of obstacles in the trajectory of the toxic cloud and in the diffusion of pollutants transported, together with a dynamical information of the potentially affected population and their associated symptoms, contribute to a better planning of the protecting measures and of the responses. Any detail included to study vulnerabilities, capabilities of response and possible menaces is crucial for risk management.

\section{Acknowledgments}

This work was supported by the National Council of Scientific and Technical Research (CONICET), the Commission for Scientific Research of the Province of Buenos Aires (CIC-PBA) and the UBACYT 20020100100536 grant. A. Porta is member of the research career of CIC-PBA and J.E. Colman Lerner has a scholarship from CONICET. 
We thank Hanna et al. (2009), who kindly authorized us to use their data and runs, and thus to carry out the objectives of this paper. Also, we thank M. Gonzalez and the Department of Modeling and Crisis Management (CITEDEF) for their helping in the implementation of the models.

Finally, we thank J.L. Colman Lerner for valuable discussions and help in the preparation of the final version of this article.

\section{References}

Acquesta, A.D., Sanchez, E.Y., Porta, A., Jacovkis, P.M., 2011. A method for computing the damage level due to the exposure to an airborne chemical with a timevarying concentration. Risk Anal. 31 (9), 1451-1469.

Amoore, J.E., Hautala, E., 1983. Odor as an aid to chemical safety: odor thresholds compared with threshold limit values and volatilities for 214 industrial chemicals in air and water dilution. J. Appl. Toxicol. 3, 272-290.

Beychok, M., 1994. Fundamentals of Stack Gas Dispersion, third ed.. Irvine, CA.

Craig, D.K., Davis, J.S., Hansen, D.J., Petrocchi, A.J., Powell Jr., T.J., Tuccinardi, T.E., 2000. Derivation of temporary emergency exposure limits (TEELs). J. Appl. Toxicol. 20, 11-20.

Dandrieux, A., Dimbour, J.P., Dusserre, G., 2006. Are dispersion models suitable for simulating small gaseous chlorine releases? J. Loss Prev. Process Indust. 19, 683-689.

Delaunay, D., 1996. Numerical simulation of atmospheric dispersion in an urban site: comparison with field data. J. Wind Eng. Ind. Aerodyn. 64 (2-3), 221-231.

Doury, A., 1988. A design basis for the operational modelling of atmospheric dispersion. J. Loss Prev. Process Indust. 1, 156-162.

ERPG and WEEL, 2007. American Industrial Hygiene Association. Emergency Response Planning (ERPG) and Workplace Environmental Exposure Level (WEEL) Committees. Emergency Response Planning Guidelines (ERPG) \& Workplace Environmental Exposure Levels (WEEL) Handbook. AIHA, Washington, DC

Fauske, H.K., Epstein, M., 1988. Source term considerations in connection with chemical accidents and vapour cloud modelling. J. Loss Prev. Process Indust. 1, $75-83$.

Gavelli, F., Bullister, E., Kytomaa, H., 2008. Application of CFD to LNG spills into geometrically complex environments. J. Hazard. Mater. 159 (1), 158-168.

GexCon US, 15 August, 2012. FLACS CFD. http://gexconus.com/FLACS_CFD (online).

Hanna, S.R., Drivas, P.J., 1987. Guidelines for the Use of Vapour Cloud Dispersion Models. CCPS/AIChE, New York.

Hanna, S.R., Strimaitis, D.G., 1988. Workbook of Test Cases for Vapour Cloud Source Emission and Dispersion Models. CCPS/AIChE, New York.

Hanna, S.R., Hansen, O.R., Dharmavaram, S., 2004a. FLACS CFD air quality model performance evaluation with Kit Fox, MUST, Prairie Grass, and EMU observations. Atmos. Environ. 38 (28), 4675-4687.

Hanna, S.R., Hansen, O.R., Dharmavaram, S., 2004b. Evaluation of FLACS CFD Model with MUST Data. AMS meeting. Vancouver, Canada.

Hanna, S.R., Dharmavaram, S., Zhang, J., Sykes, I., Witlox, H., Khajehnajafi, S., Koslan, K., 2008. Comparison of six widely-used dense gas dispersion models for three recent chlorine railcar accidents. Proc. Saf. Prog. 27, 248-259.

Hanna, S.R., Hansen, O.R., Ichard, M., Strimaitis, D., 2009. CFD model simulation of dispersion from chlorine railcar releases in industrial and urban areas. Atmos. Environ. 43, 262-270.

Hansen, O.R., Melheim, J.A., Storvik, I.E., 2007. CFD-modelling of LNG dispersion experiments. In: Proceedings of 7th Topical Conference on Natural Gas Utilization, AIChE Spring Meeting, Houston.

Hjertager, B.H., 1985. Computer simulation of turbulent reactive gas dynamics. J. Model. Ident. Contr. 5, 211-236.

Hjertager, B.H., 1986. Three-dimensional Modelling of Flow, Heat Transfer, and Combustion. In: Handbook of Heat and Mass Transfer. Gulf Publishing Company (Chapter 4).

Hjertager, B.H., Bjørkhaug, M., Fuhre, K., 1988a. Gas explosion experiments in 1: 33 scale and 1:5 scale; offshore separator and compressor modules using stoichiometric homogeneous fuel-air clouds. J. Loss Prev. Process Indust. 1, 197-205.

Hjertager, B.H., Bjørkhaug, M., Fuhre, K., 1988b. Explosion propagation of nonhomogeneous methane-air clouds inside an obstructed $50 \mathrm{~m}^{-3}$ vented vessel. J. Hazard. Mater. 19, 139-153.

Long, H.J., Zajaczkowski, F.J., Haupt, S.E., Peltier, L.J., 2009. Modelling a hypothetical chlorine release on a college campus. J. Comput. 4 (9), 881-890.

MANHAZ, 2006. Models and Techniques for Health and Environmental Hazard Assessment and Management. In: Markiewicz, Part 2.4: Mathematical Modelling Heavy Gas Dispersion. Otwock-Swierk, Poland.

National Research Council, 2001. Standing Operating Procedures for Developing Acute Exposure Guideline Levels for Hazardous Chemicals. The National Academies Press, Washington, DC.

National Research Council, 2004. Acute Exposure Guideline Levels for Selected Airborne Chemicals, vol. 4. The National Academies Press, Washington, DC.

Official Website for the State of Illinois, 15 August, 2012. http://www.state.il.us/dcfs/ post_adoption/map.asp (online)

Reynolds, R.M., 1992. ALOHA Theoretical Description; Draft. In: Technical Memorandum NOS ORCA-65. Hazardous Materials Response and Assessment Division (HMRAD) of the National Oceanic and Atmospheric Administration (NOAA), Seattle, WA.

Ruiz Boada, F., González Ferradas, E., Miñana Aznar, A., 2003. Planning Areas to Serious Accidents with Toxic. In: Technical Guide (in the Area of Royal Decree 1254/99 [Seveso II]). Universidad de Murcia, Murcia.

Sanchez, E.Y., 2012. Formulación, implementación y acoplamiento de un modelo de exposición aguda a una nube tóxica con modelos de propagación de contaminantes en aire, para su aplicación en emergencias químicas. PhD Thesis, Universidad Nacional de La Plata, Argentina.

Sanchez, E.Y., Acquesta, A.D., Porta, A.A., Jacovkis, P.M., 2010. Simulation of chemical accidents: assessment of exposure to non-stationary models. In: Proceedings of the I Congreso Latinoamericano SRA-LA 2010: "El estado del análisis de riesgo en América Latina".

Sanchez, E.Y., Gonzalez, E.M., Porta, A.A., Jacovkis, P.M., Acquesta, A.D., 2011. Simulation of a chemical incident with the tool CFD-DDC: emergency response planning in cities. In: Puliafito, E. (Ed.), Contaminación Atmosférica e Hídrica en Argentina. Universidad Tecnológica Nacional, ISBN 978-950-42-0136-6, pp. 257-268.

Sanchez, E.Y., Gonzalez, E.M., Colman, J.E., Porta, A.A., Jacovkis, P.M., Acquesta, A.D., 2012a. Model and simulation of regions affected by a chemical incident. In: Ciencia y Tecnología Ambiental, un enfoque integrador. Asociación Argentina para el Progreso de las Ciencias, ISBN 978-987-28123-1-7, pp. 333-338.

Sanchez, E.Y., Acquesta, A.D., Colman Lerner, J.E., Porta, A.A., Jacovkis, P.M., 2012b. Analysis with DDC coupled to different models of dispersion in air of chlorine releases. In: Muñoz, F. (Ed.), Proceedings of the Second Congress SRA-LARegional Society for Risk Analysis-Chapter Latin America, pp. 119-125.

Sklavounos, S., Rigas, F., 2005. Simulation of Coyote series trials - part I: CFD estimation of non-isothermal LNG releases and comparisons with box-model predictions. Chem. Eng. Sci. 61, 1434-1443.

Stage, S.A., 2004. Determination of acute exposure guideline levels in a dispersion model. J. Air Waste Manag. Assoc. 54, 49-59.

US EPA, 2012a. Acute Exposure Guideline Levels Program. http://www.epa.gov/ oppt/aegl/ (online)

US EPA, 2012b. CAMEO: Downloading, Installing, and Running ALOHA. http://www. epa.gov/oem/content/cameo/aloha.htm (online)

US EPA, 2012c. Human Exposure Modeling - General Information. http://www.epa. gov/ttn/fera/human_gen.html (online).

US EPA, 2012d. Modeling Improves Understanding of Human Exposure to Air Pollutants. http://www.epa.gov/ord/ca/pdf/ca-factsheet-expmodel.pdf (online).

US EPA, 2012e. Support Center for Regulatory Atmospheric Modeling. http://www. epa.gov/scram001/ (online)

Warner, S., Platt, N., Urban, J.T., Heagy, J.F., 2008. Comparisons of transport and dispersion model predictions of the joint urban 2003 field experiment. J. Appl. Meteorol. Climatol. 4, 1910-1928.

Wendell Cox Consultancy, 15 August, 2012. Chicago Neighbourhoods: Population \& Population Density: 1980 to 2000. http://www.demographia.com/db-chinhd2000.htm (online). 